\title{
Buffer Zone: Policies, Procedures, and Reality
}

\section{Ceyda Mumcu, Gil Fried, and Dan Liu*}

\begin{abstract}
The term 'buffer zone' has been used roughly for the past 20 years to highlight the space needed between an activity area and its surrounding to present the safest activity area possible. While everyone would agree there should be some space, the issue is how much? Is the designated space just an estimate or based on scientific research? If there had not been any prior injuries for many years, is the facility reasonably safe for the activity level? These are the questions that exist around "appropriate" buffer zones. This paper examines the basketball buffer zones and whether they are accurate and appropriate. After providing background information about the role of buffer zones, risk management basics, and basic physics of movement, this paper attempts to provide the most appropriate basketball buffer zone distance via surveys, player measurements, and a dose of physics.
\end{abstract}

Keywords: buffer zone, safety, basketball, risk management

\section{Introduction}

On a regular basis athletes leave the playing area during a basketball competition and need additional space for their and others' safety. In one famous example, LeBron James jumped for a ball heading out of bounds and landed on professional golfer Jason Day's wife, injuring her (Vardon, 2015). In another example, James was fouled by an opponent and the resulting tumble sent him out of bounds, causing him to cut his head on a courtside photographer's camera (Amick, 2015). Although in these examples falling out of bounds did not result in significant or permanent harm, such injuries are certainly possible. During a basketball practice in 2001, a 16-year-old girl stepped on a ball and was propelled by her motion into an unpadded wall, less than six feet away from the baseline. She suffered a traumatic brain injury and ended up recovering a settlement from the high school (Seidler, 2013). In another case, a 14-year-old girl took a charge during a practice and fell backwards, hitting her head against a wall four feet from the baseline. She also suffered traumatic brain injuries, and was able to recover a significant

\footnotetext{
${ }^{*}$ Ceyda Mumcu, PhD, is an assistant professor in the Sport Management Department at the University of New Haven; email: cmumcu@newhaven.edu. Gil Fried, JD, is the chair of the Sport Management Department at the University of New Haven. Dan Liu, PhD, is an assistant professor in the Department of Physics at the University of Hartford.
} 
settlement from the school district, coach, and athletic director (Seidler, 2013). These are just some examples of the significant harm caused when basketball players come in contact with a wall or other dangerous object located too close to the basketball playing area. These incidents can result in serious injuries and possible lawsuits claiming a facility was dangerous or a program administrator acted inappropriately by allowing the game/practice to be played without enough of a buffer zone. For many of the lawsuits, the facility was able to avoid liability by showing they met/exceeded minimum "buffer zone" mandates established by various associations or organizations.

The "buffer zone" is a term of art used by many sport law educators, but it refers to a safety area around a playing field or court. Buffer zones exist in all sports as it is very difficult for an athlete to compete on a field, court, or other playing surface without going outside of the playing lines. Buffer zones are needed to provide additional space to the athletes in case they go outside the lines. The question is, what is an appropriate buffer zone?

This is a topic of significant debate, and there have been a number of lawsuits over the years trying to determine what an appropriate buffer zone is, and what risk management steps can help reduce collision risks (Steinbach, 2004, 2006). The focus in a lot of these cases is what the distance of a buffer zone should be, and where protective padding should be located. Such focus, while important, has not really examined the underlying issues in terms of how the sport of basketball is played (especially at various levels), and the mechanics of injuries to determine the most appropriate buffer zone distance and whether padding really provides a benefit.

For example, a study by the National Athletic Trainers Association concluded that $22 \%$ of all male basketball players annually sustained at least one injury resulting in time lost during the season. Sprains were the most common type of injury (43\%), followed by general trauma (22\%). Interestingly, $60 \%$ of the accidents happened during practice, and 59\% of game-related injuries occurred in the second half of a game (Seidler, 2013). It can be assumed that during practice players might push themselves to improve, opening themselves up to more injuries. Also, fatigue can contribute to more players getting injured in the second half of a game. Another potential explanation for the late-game injuries is that opponents often play more aggressively in close games, and such plays/fouls could cause a potential injury. However, rather than speculate, a scientific approach relying on actual data should be used to develop the best risk management strategy. That is why determining the best buffer zone distance using science is so critical. Thus, the purpose of this study was to use physics to help identify the ideal buffer zone that would provide the greatest safety for players beyond the baseline in basketball courts. 


\section{Review of Literature}

\section{What Testing Has Been Done?}

The authors have been unable to find any published articles examining appropriate buffer zones through scientific calculations. Some research has been undertaken in relations to foam padding and the amount of force they should withstand. An article in 2004 examined the conclusions reached by the American Society of Testing Material (ASTM) on foam padding (Steinbach, 2004). The test involved dropping a sensor-equipped steel missile from a predetermined height onto several thicknesses of wall padding to assign each padding a G-max rating. The G-max rating is a measurement of how abruptly the missile stops upon impacting the padding. A G-max rating of 200 is the benchmark on which all wall pads should be judged, and the lower the G-max rating the safer the padding. In 2002, Promats, a manufacturer of athletic safety equipment, conducted its own tests on its padding as well as on competitors' padding. Promats determined that a drop height of 11 feet (compared with three feet used by ASTM) best replicates the speed at which an athlete running a 4.4-second 40-yard dash would hit a padded wall in full stride (Steinbach, 2004). The ASTM adopted this conclusion and has since modified standards associated with wall padding a number of times (ASTM International, 2004).

Another research study was conducted by Todd Seidler (2009) to identify appropriate buffer zones around a basketball court with a sample of sport law professors. The professors were asked to rate how safe different buffer zones were with and without padding. The survey results showed 27 of 51 respondents (53\%) indicated a three-foot buffer zone was "very unsafe," while another 22 called it "unsafe" or "marginally unsafe." No respondent considered three feet to be "very safe" or even "safe." When asked what the minimum required distance should be between a court baseline and an unpadded wall or obstruction, 41 respondents $(80 \%)$ identified at least 10 feet. When full padding is added to the survey questions, 22 respondents $(43 \%)$ indicated that the buffer zone still should be at least 10 feet, while 24 respondents (47\%) chose something between six and eight feet, and five respondents chose five feet (Steinbach, 2006). It should be noted Seidler (2009) has advocated for a 10-foot buffer zone whenever possible.

These studies indicated how padding is critical for protecting players, but did not address the issue of where padding should be placed and what benefits the pads provide when a player dives or is pushed/bumped out of bounds rather than running into a wall. Also, it is easy for people to speculate what is safe, but it is imperative to support such hypotheses with actual testing.

\section{Risk Management}

An owner or possessor of land owes, to all persons legally on the premises, a duty to maintain the property in a reasonably safe condition and to warn visitors of unreasonable dangers of which the landowner is aware or reasonably should be aware (Cobb et al. v. Town of Blowing Rock, 2012; O'Sullivan v. Shaw, 2000; Schneider v. American Hockey, 2001). The duty to warn normally does not extend to dangers obvious to persons of average intelligence. Thus, an owner 
must take ordinary care to keep the premises in reasonably safe condition for its users, participants, and spectators. It does not need to be perfectly safe, just reasonably safe.

A jury makes the determination of the standard of care required by a reasonable landowner by considering the totality of the circumstances in a particular case. These circumstances may include the location, the time of day, lighting conditions, facility type, and even the foreseeable characteristics of lawful visitors. These are all factual determinations and evidence as to all of these factors are relevant in the determination of what is "reasonable" (Cobb et al. v. Town of Blowing Rock, 2011).

An expanded scope of what constitutes a reasonable facility can be found in the Ford v. Bd. of Cnty. Comm'rs (1994) case. The court concluded a landowner or occupier of premises must act as a reasonable person in maintaining his/her property in a reasonably safe condition in view of all the circumstances, including the likelihood of injury to another, the seriousness of the injury, and the burden of avoiding the risk. This duty of care extends to all persons, other than trespassers, who enter a property with the defendant's consent, expressed or implied (Ford v. Bd. of Cnty. Comm'rs, 1994). Thus, a basketball player is owed a duty to make sure the basketball court is reasonably safe, and the buffer zone is part of that reasonable analysis.

One criteria reviewed in liability cases is the landowner's burden of avoiding a risk. Furthermore, the courts will examine what steps a landowner could have taken to prevent those accidents, which might foreseeably occur as the result of a dangerous condition (Kozlowski, 1996). Part of this analysis is defining a dangerous condition. Most facility managers would agree that a wall next to a playing area can be a dangerous condition. Not every risk, though, creates a dangerous condition. Facilities are normally not held liable for dangers if there are minor issues/defects (often called deminimus). Examples include Trincere $v$. County of Suffolk (1997) and Cruz v. Deno Wonder Wheel Park (2002) where a defect in the walkway was approximately $1 / 4$ of an inch. Others would probably agree that having heavy or big objects next to a court can be considered a danger to be minimized, if possible. A large or heavy object would not be considered a deminimus hazard.

One seminal case involving basketball buffer zones is Yarber v. Oakland Unified School District (1992). Anthony Yarber had played basketball in community basketball leagues from 1976 to 1985. None of the games were sanctioned or supervised by the defendant school district. During a basketball game, Yarber was hit in the act of shooting, and the impact propelled him into the unpadded concrete wall, located four feet beyond the court's baseline. He sustained a concussion, a head injury, and a temporary cervical spinal injury. The plaintiff was hospitalized after the accident, and incurred \$5,833.37 in hospital bills and $\$ 4,600$ in lost wages. The court concluded the risk of injury was inherent to the game and the school had statutory immunity protecting it from the claim. As Yarber had previously played basketball at this particular gym, the court did not examine the reasonableness of the buffer zone, but concluded based on Yarber's knowledge and experience, he should have known about the risk, and as such assumed the risk of playing basketball at that particular gym. 
When examining foreseeability of an injury and the ability to help prevent harm, guidance can be found in the concept of risk management. Risk management entails any effort to reduce the likelihood of harm to an organization. While risk management is often viewed in financial terms, it also refers to efforts undertaken to reduce the risk associated with personal injury at sporting events (Appenzeller, 2005). Risk minimization can take into consideration the cost of making the event/facility safer (if possible), changes to the event, putting up signs, providing express and implied warning to participants, or even cancelling an event (Fried, 1999). There are countless strategies that can be undertaken to reduce the risk of potential injuries. It should be noted there will always be injuries in sport due to the physical activity of participants, and the only way to eliminate these risks is to not play the games. An event administrator needs to take steps to try and minimize known risks or hazards, especially if others might not appreciate such risks. One basic risk management question is whether a landowner needs to undertake risk management steps if no one has ever been injured before at the facility. The answer depends on the facts. If it is a slight risk and the facility has not been notified of any such hazards over many years, then maybe undertaking a possible change could, in fact, enhance the risk of an injury.

Whether or not an injury is likely is an example of foreseeability. An example of this involves dog bite cases. Before a dog bites anyone, it is assumed the dog will not bite, and it is not foreseeable the dog will bite a person (depending on the breed). If the dog does bite someone, the owner will normally not be held liable for the first bite. However, after the first bite, it is now foreseeable the dog can bite. Thus, if the dog bites another person, the injured party could possibly sue because the risk of the dog biting someone is foreseeable. This is true even if the dog's owner is not sued, but rather a landlord is sued for allowing a tenant to have a dangerous dog on the landowner's property (Plowman v. Pratt, 2004; Siegel v. 1536-46 St. John's Place Corp., 1945). Risk management steps need to be taken to minimize the risk of the dog biting someone such as putting up a warning sign or keeping the dog supervised on a leash. Similar risk management steps have been taken to minimize the risk of injury on basketball courts through using buffer zones and installing padding. It is based on the assumption that a basketball player will go outside the court's baselines, and care needs to be taken to make sure foreseeable injuries are minimized or eliminated if possible.

\section{Buffer Zone Distances}

With the foreseeability of basketball players needing some room outside the court lines, there have been several attempts by various basketball rule-making bodies to promulgate rules identifying what might be an appropriate buffer zone. The Amateur Athletic Union (AAU) advocates a court measurement of 50 feet $\mathrm{x}$ 84-94 feet with 84 feet being the optimum length. The AAU also advocates a buffer zone of at least three feet with a preferred 10 feet. Its rule book specifies the National Federation of State High School (NFHS) rules apply to AAU events (Amateur Athletic Union, 2016). The NFHS Associations advocate a court measurement of 50 feet x 84-94 feet with the optimum length of 84 feet. The NFHS also advocates a buffer zone of at least three feet with a preferred 10 feet (National Federation of State High School Associations, 2009). The National 
Collegiate Athletic Association (NCAA) advocates a court measuring 50 feet x 94 feet as an official court. The NCAA also advocates a buffer zone of at least three feet with a preferred 10 feet, and suggests six feet of buffer zone behind a basket (National Collegiate Athletic Association, 2015). The National Basketball Association (NBA) does not mention a specific buffer zone around its courts (National Basketball Association, 2006). Basketball court dimensions and recommended buffer zone sizes by these associations are presented in Table 1.

Table 1. Court Dimensions and Buffer Zone Sizes of Basketball Governing Bodies

\begin{tabular}{l|c|c|c|c}
\hline & AAU & NFHS & NCAA & NBA \\
\hline $\begin{array}{l}\text { Court } \\
\text { dimensions }\end{array}$ & 50 feet $x 84-94$ feet & 50 feet $\times 84-94$ feet & 50 feet $\times 94$ feet & 50 feet $\times 94$ feet \\
\hline $\begin{array}{l}\text { Buffer zone size } \\
\text { (min) }\end{array}$ & 3 feet & 3 feet & 3 feet & No specification \\
\hline
\end{tabular}

There is no indication in any of the rule books as to how the governing bodies came up with the three-foot buffer zone. The earliest found notation of such a minimum distance is from a 1955 Wilson Sporting Goods Co. Athletic Field and Court Diagram guide (Wilson Sporting Goods, 1955). In an earlier guide from a division of Wilson published in 1952, there was no buffer zone listed for the basketball court diagram (Lowe \& Campbell Athletic Goods, 1952).

In a guide for building school facilities, Gabrielsen and Miles (1958) advocated a 10-foot buffer zone around a basketball court. The text was written by architects, not by those who operate sport facilities. The text also suggested that basketball courts be built with chalkboards on the walls and windows from an office to look into the gym. These were all possibly appropriate strategies for a high school gym in 1958, but do not necessarily reflect industry standards or best practices today. By 1966, the Athletic Institute \& American Association for Health, Physical Education and Recreation was also advocating three feet minimum for a buffer zone.

All these efforts to establish a buffer zone, even if not explicitly written, are designed to provide as safe an environment as possible for the participants. Even if risk management steps are not obviously needed, landowners often warn people about possible risks. Such warnings can include express warnings (such as yelling "watch out for the walls") or can entail signs, painting the walls a bright color, and/or padding the walls. The easiest solution is to warn a participant, but this strategy can be difficult to track when some players might have been playing in the gym for years and might and/or should have known about the walls/objects and how far they are from the basketball court.

\section{Duty to Warn}

As previously mentioned, a landowner has the duty/obligation to warn of known risks or hazards about which others might not know or appreciate. The warning needs to be specific, so those reading the sign should understand the risk, especially if the hazard is significantly more dangerous than it appears (Walter $v$. State, 1991). What if the hazard is open and obvious? There normally is no duty 
to warn individuals using a property when conditions are reasonably observable to a normal person using their senses (Kozlowski, 1996). This is especially true where the invitee is aware of, or should be aware of, the condition. Most people would say a wall behind a basketball court is an open and obvious hazard, and a reasonable person would understand and be aware of such a hazard. However, this does not mean players will always be conscious of the risk or address the risk the same way. For example, if they trip or are pushed in a direction where they might not have body control or spatial awareness, the player might not anticipate the wall behind a basketball court.

The duty to warn applies in the context of buffer zones as it is foreseeable for people to go out of bounds while playing, and, as such, it might be appropriate to provide a warning if the players might not appreciate the location of the walls or other objects. In many cases, the facts will differ; so it is hard to establish that a specific location or buffer zone might be inappropriate. The legal standard is reasonableness. A basketball court with a three-foot buffer zone with no documented history of any injuries over 50 years might be wholly reasonable. In contrast, another basketball court might have a 10-foot buffer zone, with multiple injuries over a five-year period, and such a buffer zone might not be appropriate.

\section{Physics of the Buffer Zone}

The issues of risk management and warnings reach a critical point when examined in the context of physics and how people move. A warning will have little meaning if a person cannot change his/her actions to avoid a risk caused by speed or other factors out of his/her control. As people walk or run on the ground, ground reaction force includes both normal force and friction (McLester \& St. Pierre, 2008). Normal force, $N$, is the reaction force when a force is applied, and it is always perpendicular to the surface. It is equal to weight as people who do not move and just stand on the flat ground. Friction is the reason people can walk or run. A good way to think about friction is it is easy to walk on a hard, dry surface compared to a slick surface such as ice, where there is very little friction. As a person's heel contacts the ground, the direction of friction is backward. In contrast, when toes touch the ground, friction moves forward (see Figure 1). When people increase their speed, the friction on their toes is the major force, and when people slow down, backward friction takes the main role. The friction is mainly static friction when the foot comes in contact with the surface. Static friction is a continuous curve with time as seen in Figure 2. The solid and dash waves in Figure 2 are normal force and friction, respectively. The horizontal dash line shows weight as a reference. The two peaks on the solid wave, the lowest point and the peak on the dash wave, occur when a person's heel and toes touch the ground.

Theoretically, friction could be measured by a force table or a force sensor. However, it could be very dangerous to ask participants to land on a force table when they are running at a high speed. Thus, friction needs to be measured in an indirect manner. The indirect measurement is through estimation where the static friction during the contact with the gym floor equals the maximum static friction. Maximum static friction is the product of the coefficient of static friction, , and normal force, $\mathrm{N}$. The estimation is bigger than the actual value of true 


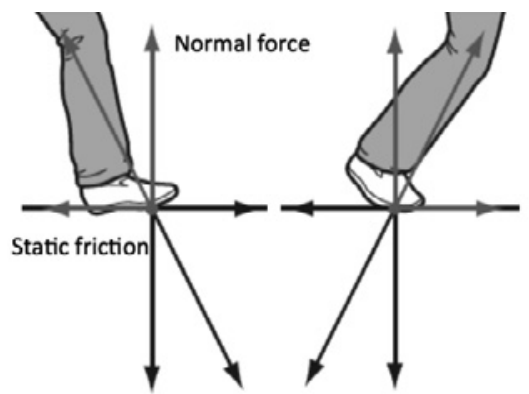

Figure 1. Friction (McLester \& St. Pierre, 2008)

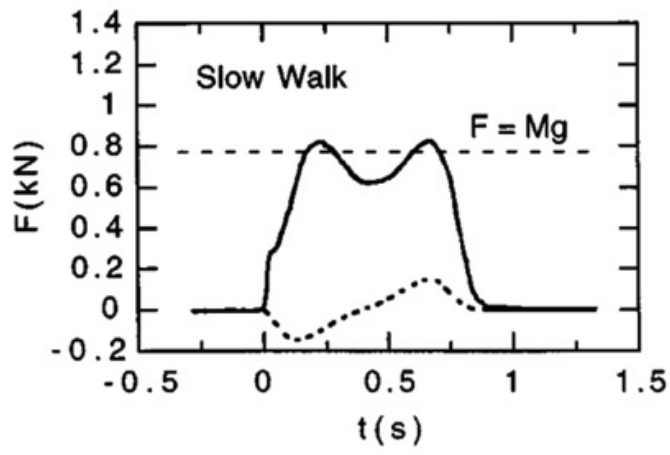

Figure 2. Presentation of friction in a graph (Cross, 1999)

friction, but it will lead to an appropriate minimum buffer zone space to serve as a reference. The coefficient of static friction is approximate $1.1 \sim 1.2$ (McLester $\&$ St. Pierre, 2008; Nigg, MacIntosh, \& Mester, 2000). Normal force is measured using a force table as participants jump up and then land on the force table.

By integrating the information in the momentum-impulse theorem (Lisa, 2016), deceleration can be calculated. The theorem is presented as $F_{n e t} \Delta t=m \Delta v$. Momentum is the product of mass (weight divided by 9.8), $m$, and velocity, $v$, and impulse is the contribution from a net force (maximum static friction), $\mu_{s}$ $N$, during a short moment of contact, $\Delta t$. Momentum-impulse theorem examines the impulse of a net force that should equal the change of momentum. This information is essential to calculate how quickly someone can slow down while running and the number of steps required to reach a complete stop. Such an analysis is critical to determine if a player can slow down with enough space to avoid contact with an object outside of a court.

$$
v_{i+1}=v_{i}-\frac{\mu_{s} N}{m} \Delta t
$$

Stride length and stride period are two additional relevant measures in calculating the time and space needed for a player to stop. In biomechanics, researchers use stride length and stride period to describe the distance of a stride and the time that a person used to finish one stride. For example, the stride length and stride period in Figure 3 are 2.4 meters finished in 0.24 seconds.

Duty factor " $D$ " is another concept commonly used in running. $D$ is determined through calculating the time one foot is in contact with the ground divided by the stride period. $D$ is important because if the duty factor is large, then it means contact time is large. Based on momentum-impulse theorem, the contribution from the friction is large. Thus, the higher the duty factor, the more control people will have, and they will be able to control their motion, and speed up or slow down with fewer steps. The higher the speed, the lower the duty factor will be. For example, the duty factor in Figure 3 is 0.1 second (5.24 - 5.14 from Figure 3) divided by 0.24 seconds, which is equal to 0.417 . By undertaking such modeling, a set of discrete data can be measured and calculated. Based on the data set, a simulation was proposed to calculate the duty factor (Alexander \& Jayes, 1983). 


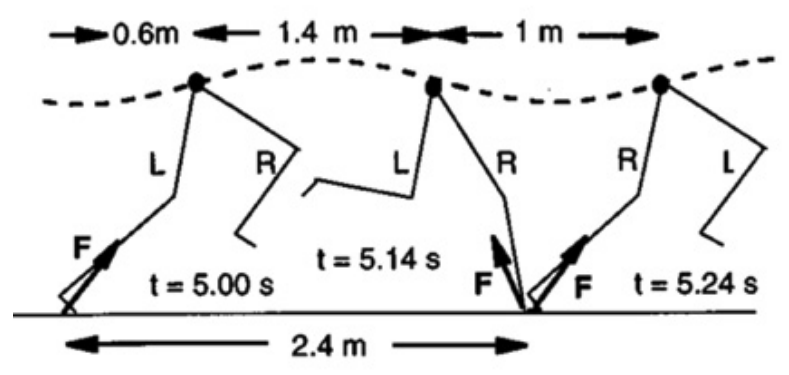

\section{L foot leaving $\quad R$ foot just landed $\quad R$ foot leaving}

Figure 3. Stride length and period (Cross, 1999)

$$
D=0.394 F r^{0.174} \text {, where Froude number, } F r=\frac{v^{2}}{g L_{l e g}} \text {. }
$$

In this equation, $g$ is standard acceleration due to gravity (Lisa, 2016), and $L_{\text {leg }}$ is length of leg, which is calculated by dividing height into two. These equations will help determine how quickly a person can slow down to possibly protect themselves from contacting a wall or other obstacle beyond a baseline or sideline.

\section{Method and Results}

Three studies were undertaken to fulfill the purpose of the investigation. The first study examined the average court size and how much space a typical gym had around the court. The second study investigated the typical mechanics of how a basketball player left the playing area and entered a buffer zone via surveying basketball coaches. Finally, the third study measured the players' height, weight, speed, stride length, and normal force in jump to calculate ideal buffer zone distance via physics. The third study also tracked the number of times basketball players went out of bounds during a recreational game and recorded the distance they traveled beyond the court to measure the actual distance needed in buffer zones as a comparison.

\section{Study 1: Gym Distinctions}

As indicated in the literature review, recommendations for the size of buffer zones are inconsistent, and every gym is different. Students in a sport law class were asked to undertake measurements of their high school gyms to present variations in court dimensions, buffer zones, and wall padding. The focus of the measurements were high school gyms due to their accessibility to the students and the limited requirements of formal requests for such measurements. A total of 34 gyms throughout New England were measured, and the construction date of the gyms ranged from 1900 to 2010. Thus, many gyms are grandfathered in on

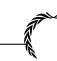


their size, and any change might be limited without incurring significant expense of building a new gymnasium or undertaking a major renovation. Half of the gyms $(n=17)$ were manufactured using bricks with the next largest category being cement walls $(n=10)$. Fourteen courts measured exactly or very close to 84 feet by 50 feet, which were the recommended dimensions by the AAU and NFHS associations. Some gyms were much smaller (19 feet long) and some were over 90 feet long. The average buffer zone behind a basket was 10.3 feet $(S D=8.1)$. However, this calculation included four outliers. Three gyms had only one foot of a buffer zone behind the baseline, and one gym had 45 feet of a buffer zone. When these extremes were removed from the calculation, the average buffer zone behind a basket became 9.8 feet $(S D=5.1)$. Ten gyms had buffer zones of greater than 13 feet behind the baseline, while 12 gyms had less than six feet. The average buffer zone along the sidelines was 6.3 feet $(S D=5.1)$. This number can be misleading as calculations varied in some gyms based on whether bleachers were extended or not. In some gyms, the bleachers were extended, and as a result, the sideline buffer zones were two feet in width. In total, $13 \mathrm{gyms}$ had sideline buffer zones of three feet or less. Finally, the wall padding behind the baseline was measured; seven gyms did not have wall padding, while the rest had padding behind the baseline. The average padding height was six feet $(S D=1.1)$, and average thickness of the padding was 1.8 inches $(S D=.9)$. Only five of the gyms had sideline padding.

Seven of the 34 gyms had records of a player being injured while hitting something beyond the sideline or baseline. One of the gyms, with five documented injuries, had a buffer zone of 12 feet on the baseline and 11 feet on the sideline without any padding. One gym with a 10-foot buffer zone had an athlete crash into an unpadded brick wall, and as a result the school padded the wall. Another gym had extended the bleachers, and an athlete injured his knee on the bleachers. Yet another gym reported a concussion injury from an athlete hitting a padded wall.

\section{Study 2: Accident Mechanics}

High school and college basketball coaches from the tristate area of New England were invited to take a survey via an email to identify how and why athletes exit a basketball court beyond the baselines and sidelines. A total of 15 basketball coaches responded to the survey in a two-week span. The respondents ranged from 4 to 30 years of coaching experience, with an average of 12 years of experience $(S D=7.92)$. Of these coaches, $6.7 \%$ coached high school junior varsity, $33.3 \%$ coached high school varsity, and $60 \%$ coached college basketball. Finally, $46.7 \%$ of the coaches were women's basketball coaches, 53.3\% were men's basketball coaches, and 3.8\% (1 respondent) coached both genders.

Coaches identified speed of a lay-up (13.3\%), being fouled (20\%), and diving for a ball to keep a loose ball in the game (40\%) as the frequent and very frequent reasons for players traveling beyond the baseline of a basketball court. A similar question referring to the sidelines reported being fouled $(7.1 \%)$ and diving for a ball to keep a loose ball in the playing area (35.7\%) as the most common reasons for players leaving a court. In addition to the reasons for falling out of bounds, coaches were asked to identify where the athletes' movements began (often and 
always) for players leaving the court at the baseline. See Table 2 for the reasons players went out of bounds at the baseline and their respective movement span on the court. For the sideline cases, coaches were asked the number of approximate steps taken by the athletes before leaving the court. The results were as follows: 2 to 10 steps $(M=3.5, S D=2.1)$ for being fouled and 0 to 7 steps for diving for a ball to keep it in play $(M=2.75, S D=1.6)$. Although researchers aimed to identify the scenarios to mimic and measure in the third study, the survey findings revealed a need to collect measurements during an actual game as demonstrations in a practice session would not provide accurate pace and game conditions.

Table 2. Reasons of Falling Out of Bounds at Baseline

\begin{tabular}{l|c|c|c|c}
\hline & Full Court & Half Court & 3-Point Line & 3-Second Zone \\
\hline Speed of lay-up & $7.7 \%$ & - & $9.1 \%$ & $36.4 \%$ \\
\hline Being fouled & $30.8 \%$ & - & $27.3 \%$ & $36.4 \%$ \\
\hline Loose ball chase & $16.7 \%$ & $25 \%$ & $30.8 \%$ & $45.5 \%$ \\
\hline
\end{tabular}

\section{Study 3: Physics Study}

The purpose of the third study was to determine the minimum distance a person would need to slow down after reaching different running/playing speeds to stop in a timely manner without hitting the wall/object beyond the playing court. The precondition of the minimum distance analysis is that players try their best to control their motion and stop themselves. Furthermore, players will try to run as fast as possible to beat their competitors to a basket, the ball, or a given position. No one wants to collide with a wall or other object, so players tend to slow down with enough time to reduce the chance of a collision.

Sample. In order to calculate the ideal buffer zone distance via a physics model, data was collected from players during a recreational basketball game. Recreational players were chosen for the study due to their willingness and availability to participate. In addition, recruiting college basketball players to participate in this study was difficult with coaches' unwillingness and teams' restrictions on additional sport participation. Finally, while high school and college basketball games are sanctioned and have regulations pertaining to buffer zones and wall padding, recreational leagues and games do not have regulations. Therefore, perhaps participants are more prone to injuries. Eleven basketball players participated in the study through playing a competitive basketball game for two, 20-minute halves on an 80-foot x 54-foot court using referees and a time clock. Among the 11 players, one played college basketball, seven played varsity high school basketball for an average of 3.3 years, and four played basketball only recreationally.

Measurements. Prior to the game, players' height, weight, stride length, and maximum normal force in jumping were collected. Athletes' height and weight were measured with a traditional tape measure and a scale. To measure the stride length, athletes were asked to stand behind a line and take a step along a measuring tape. Athletes' maximum normal force was measured on a force plate, where athletes were asked to stand on the plate balancing their weight on 
both feet and jump as high as possible. Each athlete had three attempts, and the force plate recorded their normal force for each attempt. An average of normal force for each athlete was calculated by taking the average of three recordings.

Throughout the game, athletes' speed, number of occasions participants went out of bounds, and the distance they traveled when they went out of bounds were tracked. Athletes' speed was tracked with speed (radar) guns. Researchers recorded the speed readings on a tracking sheet as athletes ran back and forth throughout the game. The distance traveled in buffer zones were measured with tape markings placed on the floor between the baseline and the wall (i.e., one-foot, two-foot, and three-foot markers). The researchers used tally sheets to track how often, and what distance, players traveled in the buffer zones throughout the game.

Physics analysis. The measurements taken were used to help calculate the time required to slow from the maximum speed reached by players during the game given their height, weight, force, and speed. Researchers consider maximum static friction as the contact time of a foot on the ground. They also defined the highest speed as $V_{0}$, the according stride length as $l$, and the duty factor as $D_{0}$. In the first stride after slowing down, the speed slows down to $v_{1}$, the according stride length is $x_{1}$, and duty factor is $D_{1}$. In the next stride undertaken to slow down, the speed and the stride length are $v_{2}$ and $x_{2}$, respectively. The third and further strides are labeled in the same way with the assumption that a player will normally come to a full stop after his/her fourth stride, but can stop sooner.

The contact time calculated from the stride before a player starts slowing down equals the time between the first and second step when a player attempts to slow down. Physicists can express and calculate from the following Equation 3, and Equation 1 and 2.

$$
\frac{l}{v_{0}} D_{0}=\frac{x_{1}}{v_{1}} D_{1}
$$

Following the iteration $v_{i}$ and $x_{i}$ can be calculated, where $\mathrm{i}=1,2, \ldots$ The minimum distance for buffer zones $x_{\text {total }}$ is the sum of all $x_{\mathrm{i}}$ before the player is able to control his/her motion. Researchers used the speed limit of walking from the model of simple pendulum, $\sqrt{g L_{l e g}} \pm 5 \%$ as the component for identifying critical speed, approximately $6.71 \pm 0.34$ miles per hour (mph) (Nigg, MacIntosh, $\&$ Mester, 2000). As the speed slows below $\sqrt{g L_{l e g}}$, we stop the iteration.

Results. The players' height ranged from 5.8 feet to 6.10 feet with an average of 5.9 feet $(S D=.39)$, and their weight ranged from 160 pounds to 220 pounds with an average of $175.6(S D=30.7)$. Their stride length varied between 1.7 feet to 2.3 feet with an average of $1.98(S D=.21)$. Finally, players' average normal force ranged from $1665.4 \mathrm{~N}$ to $2984.8 \mathrm{~N}$ with an overall average of $2191.9(S D=439.3)$. It is important to remember, these descriptive statistics are provided to display overall physical characteristics of the participants, and this raw data was used in the physics calculations.

Using the measurements from the players and the speed gun readings of running around the court, the physics data modeling produced the final results presented in Table 3. The players reached the highest speed when they had a full sprint across the court. That speed was around 21 miles per hour (mph). Of the 35 speed gun measurements, 16 involved layups while the rest entailed players just running (possibly to obtain a pass or defend the basket, as examples). Taking 
a total of 35 measurements, the average speed for these players was $19.57 \mathrm{mph}$ at full speed. When these players tried to slow down, their first stride in an effort to stop was $15.37 \mathrm{mph}$, and the second stride was $11.18 \mathrm{mph}$. As can be seen in Table 3 , when the players were trying to slow down, they traveled an average of 4.69 feet in their first stride and 3 feet in their second stride. Thus, players needed on average 7.74 feet of space to stop their movement safely. It is impossible to stop immediately, and, when someone is running at almost $20 \mathrm{mph}$, it will take time and distance to slow down, thus the need for buffer zones. It should be noted the baskets in this study were hung from the ceilings and extended four feet onto the court. Thus, when a player was attempting a lay-up, the player had possibly four feet of runoff before hitting the baseline and then the buffer zone area. The four feet area is still part of the playing area, as action can occur between the baseline and behind the basket as part of the game.

Table 3. Results via Physics Modeling

\begin{tabular}{lccccc}
\hline & Average & 3-Point Line & Half Court & Full Court & Lay-up \\
\hline Number of cases & 35 & 13 & 11 & 12 & 16 \\
$\nu 0(\mathrm{mph})$ & 19.57 & 17.39 & 20.09 & 21.64 & 18.88 \\
$v 1(\mathrm{mph})$ & 15.37 & 12.46 & 16.04 & 17.96 & 14.47 \\
$x 1(\mathrm{ft})$. & 4.69 & 4.13 & 4.79 & 5.05 & 4.53 \\
$v 2(\mathrm{mph})$ & 11.18 & 7.54 & 11.99 & 14.29 & 10.06 \\
$x 2(\mathrm{ft})$. & 3.05 & 2.10 & 3.25 & 3.71 & 2.79 \\
$v 3(\mathrm{mph})$ & 6.96 & 2.62 & 7.94 & 10.63 & 5.64 \\
$x 3(\mathrm{ft})$. & & & 1.87 & 2.49 & \\
$v 4(\mathrm{mph})$ & & & 3.87 & 6.96 & \\
$x_{\text {total }}(\mathrm{ft})$. & 7.74 & 6.27 & 9.88 & 11.25 & 7.32 \\
\hline
\end{tabular}

Based on the data collected throughout the simulated game, the players left the court under the basketball hoop 19 times on either side of the court. The athletes who went out of bounds in these 19 instances traveled on average 5.18 feet $(S D=4)$. Since players, generally, do not go out on the sidelines as frequently and with the same velocity or speed both during games and in this study, the players who exited the sidelines only went on average 3.28 feet $(S D=2)$ beyond the sidelines. However, one of these instances involved a player going over 10 feet beyond the sideline, so the data are skewed by that one instance. Players tended to travel farther out of bounds when chasing a loose ball compared with shooting a lay-up. See Table 4 for the data from direct measurement of players moving on the court and entering the buffer zone. 
Table 4. Frequency of Falling Out of Bounds and the Distance Traveled

\begin{tabular}{lcccc}
\hline & Baseline & Sideline & Loose Ball Chase & Lay-up \\
\hline Number of cases & 19 & 5 & 11 & 10 \\
Ave. Out-of-bounds distance, $\mathrm{x}(\mathrm{ft}$.) & 5.18 & 3.28 & 5.15 & 5.00 \\
\hline
\end{tabular}

The calculated buffer zone distances in Table 3 are higher than the direct measurements in Table 4. The model in the authors' calculation is based on the situations where the highest speeds occur up to the baselines. The calculation theoretically provides the minimum safe buffer zone distance. Although the aforementioned situations in the model do not commonly happen, the model provides a more conservative measurement that could provide safer basketball courts. Risk management strategies are not implemented to address every risk, just the most common risks and the most dangerous circumstances.

\section{Discussion}

Based on the results of the study, it is important to have buffer zones to help reduce the possibility of injuries and reduce possible legal concerns. While different organizations have published rules for buffer zones, none of these rules were based on scientific analysis. Through examining how much space basketball players needed to slow down, the authors recommend there should be a minimum five-foot buffer zone behind a basket and 3.5 feet along the sidelines. For even more safety, the authors recommend an eight-foot buffer zone behind the basket.

As previously highlighted in this text, every facility is different and these are general suggestions that may not be applicable to all gyms. Every gym owner has to examine the facility's circumstances and history to determine what is appropriate. Any existing facility with a small buffer zone should consider adding protective measures such as padding to increase protection. All buffer zone related injuries should be tracked to determine any possible trends or more common occurrences, and whether the safety distances calculated in this paper are appropriate for a given facility. Any analysis should take into consideration factors such as gym size, participant size/speed, gym configuration, and similar variables. Future facilities, if at all possible, should try to have a buffer zone closer to 8 to 10 feet to provide the highest level of protection for the most extreme potential collisions. By looking at 34 different gyms, it was determined that many gyms were over 40 years old. These gyms were primarily high school sized, and had an average distance of baseline buffer zones beyond the three feet of buffer zone advocated as minimums in several basketball rule books. However, there were a number of gyms with buffer zones shorter than what this research would indicate as safe. The sample also reported several gyms with more than 10 feet of buffer zones, yet several players still contacted a wall/object. This helps highlight that having a large buffer zone does not guarantee complete safety for players.

Coaches indicated how players left the court based on their experience. Although coaches felt most players left the playing area when diving for balls, the researchers in this study did not observe a single player dive for a ball during 
the simulated game. A majority of players left the court after completing a lay-up or similar play, and only a handful left the playing area due to a foul. The coaches' perceptions might be from what they see on a regular basis. Since a player leaving the court area happens so frequently, the coaches might not think about regular plays, but responded with extreme plays they remembered.

It should be specifically noted the researchers were not able, nor would it be feasible, to measure the power that could be generated by a foul. Similarly, players were not tested diving out of bounds and the distance or power they might have in such situations. Some players leave the court based on very forceful fouls that are hard to replicate. Similarly, numerous collisions and accidents occur that can affect a player's movement and control. Based on a player's size and strength, he/she can dive at different speeds and with different power. These areas would also be hard to measure.

Further research might help identify the impact of wall padding, what impact padding might have on the necessary buffer zone, where the padding should be located (height and location), and how thick the padding should be to offer maximum protection. This study strictly examined the amount of space needed for players to slow down based on traditional basketball movements. By adopting at least a 5.2-foot buffer zone (and preferably an eight-foot buffer zone), most facility's can provide a safer distance for players, but this distance should be tempered based on variables highlighted in the paper such as the player's age, size, experience, and the facility's player injury history.

\section{References}

Alexander, R. McN., \& Jayes, A. S. (1983). A dynamic similarity hypothesis for the gaits of quadrupedal mammals. Journal of Zoology, 201, 135-152. https://doi.org/10.1111/j.1469-7998.1983. $\underline{\text { tb04266.x }}$

Amateur Athletic Union (AAU). (2016, October 11). 2017 AAU Boys' Basketball Handbook. Retrieved from http://image.aausports.org/handbooks/boys_basketball/2017_Handbook_11_07_16.pdf

Amick, S. (2015, June 12). Andrew Bogut says LeBron James jumped into cameraman. USA Today. Retrieved from http://www.usatoday.com/story/sports/nba/playoffs/2015/06/12/andrew-bogut-lebron-james-injury/71107710/

Appenzeller, H. (2005). Risk management in sport: Issues and strategies (2nd ed.). Durham, NC: Carolina Academic Press.

ASTM International (2004). Designation F2440-04 standard specifications for indoor wallffeature padding. West Conshohocken, PA: ASTM.

Cobb et al. v. Town of Blowing Rock, 713 S.E.2d 732 (N.C. Ct. App. 2011). Retrieved from http:// caselaw.findlaw.com/nc-court-of-appeals/1574386.html\#sthash.bH5RhPaW.dpuf

Cobb et al. v. Town of Blowing Rock, 722 S.E.2d 479 (2012).

Cross, R. (1999). Standing, walking, running and jumping on a force plate. American Journal of Physics, 67, 304-309. https://doi.org/10.1119/1.19253

Cruz v. Deno Wonder Wheel Park (2002). Retrieved from http://caselaw.findlaw.com/ny-supremecourt/1245658.html

Ford v. Bd. of Cnty. Comm'rs, 118 N.M. 134, 139, 879 P.2d 766, 771 (1994).

Fried, G. (1999). Safe at first. Durham, NC: Carolina Academic Press. 
Gabrielsen, M., \& Miles, C (1958). Sports and recreation facilities for school and community. Englewood Cliff, NJ: Prentice-Hall, Inc.

Kozlowski J. (1996, February). Landowner duty: Assure premises no more dangerous than it appears to be. NRPA Law Review. Retrieved from http://cehdclass.gmu.edu/jkozlows/p\%26r296. $\underline{\mathrm{htm}}$

Lisa, M. (2016). The physics of sports. Columbus, OH: McGraw-Hill Education.

Lowe \& Campbell Athletic Goods (1952). Athletic fields and court diagrams (8th ed.). Kansas City, MO.

McLester, J., \& St. Pierre, P. (2008). Applied biomechanics: Concepts and connections. Belmont, CA: Thomson Higher Education.

National Basketball Association. (2006). Rule No. 1---Court dimensions--Equipment. Retrieved from http://www.nba.com/analysis/rules_1.html?nav=ArticleList

National Collegiate Athletic Association. (2015). Men's basketball full court diagram. Retrieved from http://www.ncaa.org/sites/default/files/MBBFullCourtDiagram_20150820.pdf

National Federation of State High School Associations. (2009). Basketball court diagram. Retrieved from https://www.nfhs.org/media/727273/2009-basketball-court-diagram.pdf

Nigg, B., MacIntosh, B., \& Mester, J. (2000). Biomechanics and biology of movement (1st ed.). Champaign, IL: Human Kinetics.

O’Sullivan v. Shaw, 726 N.E.2d 951 (Mass.2000).

Plowman v. Pratt, 684 N.W.2d 28 (2004).

Schneider v. American Hockey, 342 N.J. Super. 527 (App. Div. 2001).

Seidler, T. (2009). Planning facilities for safety and risk management. In T. Sawyer (Ed.), Facilities planning and design for health, physical activity, recreation and sport (pp. 20-22). Champaign, IL: Sagamore Publishing.

Seidler, T. (2013, November 25). Basketball buffer zones: Accidents waiting to happen. Retrieved from http://www.playgroundprofessionals.com/news/parks-and-recreation/basketball-buffer-zones-accidents-waiting-happen 111

Siegel v. 1536-46 St. John's Place Corp., 57 N.Y.S.2d 473 (1945).

Steinbach, P. (2004, February). Sudden impact. Athletic Business. Retrieved from http://www. athleticbusiness.com/sudden-impact.html

Steinbach, P. (2006, March). Zone offense. Athletic Business. Retrieved from http://www.athleticbusiness.com/athlete-safety/zone-offense.html

The Athletic Institute \& American Association for Health, Physical Education and Recreation. (1966). Planning areas and facilities for health, physical education, and recreation. Chicago, IL: The Athletic Institute.

Trincere v. County of Suffolk, 688 NE 2d 489 (NY Ct. App. 1997).

Vardon, J. (2015, December 17). Jason Day’s wife accidentally injured by LeBron James in fourth quarter of Cavs win. Retrieved from http://www.cleveland.com/cavs/index.ssf/2015/12/jason days wife accidentally i.html

Walter v. State, 568 N.Y.S.2d 521 (NY Ct. CL. 1991).

Wilson Sporting Goods' (1955). Athletic field and court diagrams (11th ed.). Chicago, IL. Yarber v. Oakland Unified School Dist. 4 Cal. App. 4th 1516 (Cal: Ct. of Appeal 1992). 